\title{
АУДИТИВНОЕ ИССЛЕДОВАНИЕ ГЕНДЕРНОГО ФАКТОРА ВО ФРАЗОВОМ РИТМЕ ПРИ НЕПОДГОТОВЛЕННОМ ЧТЕНИИ ВСЛУХ (ПАРАДИГМАТИЧЕСКИЙ АСПЕКТ)
}

\section{AUDITORY ANALYSIS OF THE GENDER- BASED AGENT IN PHRASAL RHYTHM \\ DURING EXTEMPORANEOUS READING ALOUD (THE PARADIGMATIC ASPECT)}

\section{A. Bankov}

Summary: The article describes the role of the gender factor in contemporary American prosody. The attention is focused on the auditory analysis of rhythm in extemporaneous reading aloud. Typical peculiarities of the extemporaneous reading "rhythmic repertoires" (the paradigmatic aspect) of each of the two gender groups are found and statistically relevant similarities and differences are defined.

Keywords: prosody, rhythm, rhythmic group, gender, extemporaneous reading, paradigm.
Банков Андрей Сергеевич

К.филол.н., дочент, Нижегородский государственный лингвистический университет им. Н.А. Добролюбова bankov2007@yandex.ru

Аннотация: Статья представляет собой фрагмент описания роли гендерного фактора во фразовой просодии современного американского варианта английского языка, в частности, результаты аудитивного анализа фразового ритма при неподготовленном чтении вслух. Для каждой из двух гендерных групп респондентов устанавливаются типичные особенности «ритмических репертуаров» (парадигматический аспект) при реализации указанного вида речевой деятельности, определяются сходства и статистически достоверные различия.

Ключевые слова: просодия, ритм, ритмическая группа, гендер, неподготовленное чтение, парадигматика.

\section{Теоретическая основа исследования}

$\mathrm{B}$ иггвистике ритм принято понимать, как «регулярное повторение сходных и соизмеримых речевых единиц, выполняющее структурирующую, текстообразующую и экспрессивно-эмоциональную функции» [5, с. 416]. Чередование ударных и безударных слогов образуют слоговый ритм. В просодических исследованиях ритм анализируется с двух позиций:

1. как изохронность ударных слогов и

2. с точки зрения свойств ритмических групп (РГ). В первом случае, как правило, применяются акустические методы анализа, во втором - аудитивные. Вспомним, что под ритмической группой понимается совокупность ударного слога и примыкающих к нему безударных слогов.

Исследование влияния гендерного фактора на ритмическую организацию фразы при неподготовленном чтении вслух с точки зрения анализа свойств ритмических групп целесообразно проводить в 3 этапа:

1. выделение ритмических групп;

2. установление их парадигматических характеристик;

3. определение их синтагматических свойств.

РГ выделяются по следующим признакам:

- слоговая РГ иерархически подчинена одной синтагме. Ситуация, когда РГ распространяется на не- сколько синтагм недопустима, но совпадение одной РГ с целой синтагмой или односинтагменной фразой вполне вероятно;

- РГ имеет только один ударный слог;

- количество и позиция безударных слогов в РГ не ограничены и влияют на типологию и свойства РГ;

- РГ, состоящие из одного ударного слога, не противоречат ни одному из вышеприведенных правил, следовательно, их существование правомерно;

- если ударный слог в РГ является ядром синтагмы или фразы, то это учитывается в обозначении и типологизации группы;

- левой границей РГ является либо начало синтагмы (или фразы, если речь идет о первой в синтагме и фразе РГ), либо начало ударного слога (если это не первая группа в синтагме);

- правой границей РГ является начало второго ударного слога в синтагме (для начальной РГ) или начало ближайшего правого ударного слога (для РГ в середине синтагмы), либо конец синтагмы/ фразы (для конечных групп);

- в случае совпадения РГ с целой синтагмой или фразой, левой и правой границами группы считаются границы соответствующей синтагмы или фразы.

Говоря о границах РГ, мы понимаем, что они совпадают с границами слогов, которые с акустической точки зрения весьма неопределенны и представляют собой, 
чаще всего, переходные области со «скользящей» артикуляцией. В настоящем исследовании, учитывая его аудитивный характер, за основное правило слогоделения принят традиционный подход, который можно охарактеризовать как аудитивно-функциональный $[1,4,6]$.

С точки зрения парадигматики каждую РГ можно охарактеризовать при помощи четырех признаков: 1) положение ударного слога по отношению к безударным или структурный тип РГ, 2) тип ударения группообразующего слога, 3) позиция РГ в синтагме и фразе, а также 4) количественный состав безударных слогов (количество проклитических и/или энклитических безударных слогов). Выявление синтагматических свойств РГ (т.е. особенностей их сочетаемости) невозможно без предварительного установления их парадигматических характеристик.

По положению ударного слога имеющиеся РГ были классифицированы следующим образом:

- Слоговая ритмическая группа, состоящая из одного ударного слога - это ударная ритмическая групnа (УРГ). Такие группы могут встречаться в начале, середине или конце фразы / синтагмы, а также полностью совпадать с ними по длине.

- Проклитические ритмические группы (ПРГ) имеют безударные слоги только слева от ударного, после него безударных слогов нет. ПРГ встречаются только в начале фраз и синтагм, и в тех случаях, когда целиком совпадают с ними.

- Энклитические ритмические группы (ЭРГ) имеют безударные слоги только справа от ударного. Встречаются в любой позиции синтагмы / фразы. Совпадение ЭРГ с фразой / синтагмой не исключено.

- Проклитико-энклитические ритмические группы (ПЭРГ) имеют безударные слоги как слева, так и справа от ударного слога. Встречаются либо в начале синтагм и фраз, либо в случаях совпадения с ними.

Тип ударения группообразующего слога позволяет установить связи между типом ударения и другими характеристиками РГ. Группе присваивалась оценка, соответствующая коду ее ударного слога, полученному на этапе описания акцентной структуры: «0» для безударного слога, «1» для словесного ударения, «2» для синтагматического ядра (СЯ), «3» для фразового ядра (ФЯ). Если применить указанный принцип описания к фразе: "It is certainly true that crime is a problem that we should try to reduce as much as possible», - то будут установлены следующие виды РГ: «lt is certainly», вида «0100»- ПЭРГ; «true», вида «2» - УРГ; «that crime is а», вида «0100» - ПЭРГ; «problem», вида «20» - ЭРГ; «that we should try to re», вида «000100» - ПЭРГ; «duce аs», вида «10»- ЭРГ; «much as», вида «10»- ЭРГ; «possible», вида «30»- ЭРГ.
Позиция РГ во фразе или синтагме важна, т.к. изменение характера синтагматического членения фразы влияет на все характеристики РГ, находящихся в непосредственной близости от границ, подвергаемых модификациям. Например, если трехсинтагменную фразу «Go sit in any courtroom for a day | and see / what cases are typically tried» произнести как двухсинтагменную - «Go sit in any courtroom for a day $\mid$ and see what cases are typically tried», то между шестой и седьмой РГ произойдет перераспределение безударных слогов, которое повлечет изменение структурных типов РГ, модификацию ударений их группообразующих слогов, а также повлияет на их мелодические контуры и длительности. Кроме того, изменение парадигматических свойств РГ обязательно повлечет модификации их синтагматических свойств, т.е. свойств сочетаемости РГ друг с другом.

В зависимости от позиции во фразе или синтагме РГ предлагается классифицировать следующим образом:

- начально-фразовые, находящиеся в начале фразы;

- начально-синтагменные, находящиеся в начале синтагмы. При этом все начально-фразовые РГ являются начально-синтагменными, но не наоборот;

- срединные, находящиеся не в начале и не в конце фразы или синтагмы;

- конечно-фразовые, находящиеся в конце фразы;

- конечно-синтагменные, находящиеся в конце синтагмы, при этом все конечно-фразовые РГ являются конечно-синтагменными, но не наоборот;

- фразовые, совпадающие с целой фразой;

- синтагменные, совпадающие с целой синтагмой, при этом все фразовые РГ являются синтагменными, но не наоборот.

Такая характеристика, как количество слогов, гипотетически допускает бесконечное множество видов и вариантов. Даже если принять во внимание ограничения, возникающие из особенностей самого языка (тенденция к моносиллабизму, особенности словообразования, характерный ритм и т.д.), количество теоретически возможных комбинаций остается слишком большим, чтобы все эти варианты можно было жестко классифицировать. Поэтому, предлагается описывать состав каждой конкретной РГ, встреченной в тексте. Совокупность описаний всех РГ текста составит массив, внутри которого можно будет сгруппировать схожие РГ. Сформированные таким образом группы РГ будут адекватной классификацией видов РГ, актуальной для данного конкретного текста. Разумеется, если иметь дело с ограниченным числом текстов, такой подход не может дать универсальной классификации, исчерпывающим образом структурирующей рассматриваемую область языка. Однако если распространить данный принцип на достаточное количество разных текстов (например, в рамках одного функционального стиля) и провести статистическую обработку результатов, то будет создана 
классификация, в целом достаточно объемная и подробная, чтобы охватить бо́льшую часть РГ в отдельно взятом функциональном стиле. При этом возможность возникновения исключений из такой классификации остается открытой. Такой анализ в масштабе языка относится к сфере больших данных и требует значительных вычислительных мощностей.

Количественный состав РГ анализируется в три шага:

1. кодировка ударных и безударных слогов цифрами «1» и «0», соответственно;

2. запись последовательностей ударных и безударных слогов в имеющихся РГ, при этом количество безударных слогов в ПРГ и ЭРГ указывается целым числом, например ПРГ вида «001» будет иметь индекс «2», а ЭРГ вида «1000» - «3». Цифра индекса соответствует количеству безударных слогов; при обозначении количества безударных слогов ПЭРГ индекс имеет форму дроби, где числитель указывает на количество проклитических слогов, а знаменатель - на количество энклитических. Например: индекс «1/3» при описании ПЭРГ означает, что данная РГ имеет вид «01000»;

3. подсчет количества РГ с совпадающими описаниями, а также определение РГ с уникальными описаниями.

Обработка данных о парадигматических свойствах каждой РГ позволит установить наиболее часто встречаемые типы и виды ритмических групп, свойственных каждой группе респондентов. Гипотеза данного этапа исследования состоит в том, что допускается, что у женщин и мужчин парадигматические свойства РГ различны. Далее ведется подсчет, сколько и каких видов РГ в соответствии с каждым парадигматичеким признаком встретилось в речи женщин и мужчин. Таким образом устанавливался «ритмический репертуар» каждой группы респондентов. Затем производились проверка фактора систематичности свойств установленных «ритмических репертуаров» внутри гендерных групп и определение статистически достоверных различий между ними.

\section{Методика исследования}

Аудитивный анализ материала проводился в два этапа: первый этап получил название «общей» части слухового анализа, а второй - «экспертной». К числу задач общей части относились: определение степени естественности звучания экспериментального материала; установление степени его соответствия нормам американского варианта английского языка General American, воспринимаемого в США в качестве произносительного стандарта; определение уровня речевой культуры (УРК) информанта. Экспертная часть аудитивного анализа проводилась с помощью авторской компьютерной программы «Просодия 1.0» $[2,3]$. Главная особенность, кото- рой в аспекте фразового ритма заключается в полной автоматизации анализа данного просодического явления.

\section{Материал исследования}

Экспериментальным материалом исследования послужили записи текстов общей продолжительностью звучания более 200 минут в исполнении 14 дикторов (7 женщин и 7 мужчин). Для проведения экспертной части аудитивного (и акустического) анализа было отобрано более 80 речевых произведений, из которых 14 представляют собой неподготовленное чтение вслух и более 70 - спонтанные диалогические реплики, что составило 65\% от общего объема собранного фактического материала. В настоящей статье рассмотрен лишь один аспект исследования.

\section{Результаты исследования}

Поскольку при неподготовленном чтении вслух все высказывания имеют примерно равную длину по количеству слогов (респонденты вслух читали один и тот же текст), то и количество РГ не должно сильно варьировать у разных дикторов как внутри групп, так и на межгрупповом уровне. Парадигматические особенности ритмических групп при неподготовленном чтении вслух анализируются в масштабах одной фразы, а не целого текста.

Анализ свойств РГ начинается с рассмотрения количественного соотношения видов РГ по признаку «положение ударного слога» (признак 1). Связано это с тем, что данный признак легче других поддается «изолированному» анализу, т.е. может быть рассмотрен в отрыве от других трех признаков и анализа РГ по признаку «количественный состав безударных слогов» (признак 4). Связано это с тем, что данные два признака легче других поддаются анализу и могут быть рассмотрены в относительной изоляции от других признаков, хотя и с рядом оговорок.

Результаты анализа положения ударного слога в РГ (признак 1): наиболее часто используемая ритмическая группа, как среди мужчин, так и среди женщин - ЭРГ, далее в порядке убывания по частоте использования следуют УРГ, ПЭРГ и ПРГ. Различия между мужским и женским вариантами в данном случае незначительны и не могут считаться достоверными, что подтверждается данными о внутригрупповой дисперсии каждого типа РГ.

Наблюдаемые в разных группах различия в суммарных показателях РГ по данному признаку не могут считаться достоверными, т.к. внутригрупповая дисперсия, как у мужчин, так и у женщин слишком велика. Ее значения, примененные к соответствующим средним показателям, значительно пересекаются. Значения вероятности каждого вида РГ в речи женщин и мужчин, 
рассчитанные с применением теории вероятности, также очень близки. Достоверные различия отсутствуют.

Следующий аспект анализа парадигматических свойств РГ - соотношение признаков структурного типа РГ (признак 1) и типа ударения группообразующего слога (признак 2). Основные различия заключаются в средних количествах УРГ со словесным ударением и синтагматическим ядром (СЯ) в качестве группообразующего слога, а также в ПРГ с СЯ и фразовым ядром (ФЯ). Однако такое различие вряд ли можно признать достоверным, несмотря на то что в относительном выражении варианты различаются иногда в разы, в абсолютном выражении разность не превышает 5-ти ритмических групп. Данный факт не может считаться однозначным и достоверным признаком различия при наличии средних сумм РГ, превышающих 150 единиц.

Вычисление внутригрупповой дисперсии рассматриваемого свойства выявляет следующие особенности. Дисперсия РГ любого структурного типа со словесным ударением у мужчин значительно превышает аналогичный показатель у женщин, в то время как «женские» показатели дисперсии РГ любого структурного типа с СЯ и ФЯ значительно превышают подобные значения у мужчин. Из этого следует, что у мужчин РГ любого структурного типа, имеющие словесное ударение в качестве группообразующего слога, сильно подвержены случайностям и иным (кроме гендерного) факторам, какаялибо системность в формировании РГ со словесным ударением отсутствует. Однако у мужчин наблюдается диаметрально противоположная ситуация с РГ, содержащими СЯ и ФЯ: они в высшей степени однообразны и системны (значения дисперсии не превышают 1,67 РГ). Иными словами, у дикторов-мужчин количество РГ со словесным ударением сильно варьирует от индивида к индивиду, имея каждый раз значительное отклонение от среднего значения. Количество РГ с СЯ и ФЯ, наоборот, практически не изменяется внутри гендерной группы, имея лишь незначительные колебания вокруг среднего значения. Данная ситуация является следствием особенностей формирования акцентной структуры.

В свою очередь, женщины «зеркально» отражают тенденцию, продемонстрированную мужчинами: дисперсия РГ со словесным ударением низка, а значения дисперсии РГ с СЯ и ФЯ очень высоки. Это означает, что количество РГ со словесным ударением у женщин практически не изменяется от диктора к диктору, на основании чего можно судить о высокой степени системности расстановки словесного ударения (а также пауз) в данной группе респондентов. Что касается РГ с СЯ и ФЯ, здесь все наоборот: количества РГ сильно варьируют, создавая значительное рассеивание вокруг среднего показателя. Это свидетельствует о высокой степени случайности и подверженности иным факторам при рас- становке женщинами смысловых акцентов. В результате текст, спонтанно читаемый вслух разными дикторамиженщинами, имеет схожий, почти идентичный слоговый ритм, но членение на смысловые отрезки (фразы и синтагмы), равно как и расположение смысловых или эмоциональных акцентов сильно варьируют. Данная характеристика ритмической организации читаемого текста является следствием особенностей формирования акцентной структуры у женщин, которая во многом зависит от расстановки пауз в тексте.

Третий этап анализа парадигматических свойств РГ рассмотрение признака «позиция РГ во фразе/синтагме» (признак 3). Данный аспект целесообразно рассматривать в связи с первым признаком - «положение ударного слога». Достоверные различия в разных гендерных группах отсутствуют. В целом наблюдается одинаковая тенденция по распределению структурных типов РГ (признак 1) по позициям в речевых сегментах (признак 3): ЭРГ - наиболее часто используемая группа в срединной позиции, ПЭРГ чаще всего применяется в начале фраз и синтагм, в конце фраз и синтагм наиболее часто используются УРГ и ЭРГ. ПРГ и ПЭРГ не бывают срединными или конечными.

В целом, значения дисперсии у мужчин, за некоторым исключением, ниже, чем у женщин, что объясняется разницей в подходах к формированию акцентной структуры читаемого текста: мужчины больше обращают внимание на фразы и синтагмы (степень регулярности распределения СЯ и ФЯ выше), женщины - на слоговый ритм. В результате, у мужчин распределение структурных типов РГ по позициям в речевых сегментах выглядит более однообразно и создает впечатление большей системности, чем у женщин. Распределение вероятностей РГ по рассматриваемому сочетанию признаков не обнаруживает существенных различий между двумя гендерными группами.

Что касается количественного состава безударных слогов в РГ (признак 4), то данный признак также рассматривался в связи с первым - «положение ударного слога по отношению к безударным или структурный тип РГ». Здесь определялось типичное количество безударных слогов, свойственное РГ различных структурных типов. У мужчин ПРГ - самая редкая группа, а ЭРГ используется наиболее часто. Тем не менее, даже среди редких ПРГ имеются подвиды, которые употребляются несколько чаще, чем другие, например: у мужчин ПРГ с одним безударным используется почти в два раза чаще, чем ПРГ с 2-мя безударными и почти в четыре раза чаще ПРГ с 3-мя безударными. ПРГ с 4-мя и 5-ю безударными слогами случайны - их доли от общего числа ПРГ составляют $2 \%$ и $0 \%$ соответственно. Их вероятности равны $0 \%$.

Наиболее часто встречаемый у мужчин вид ЭРГ имеет 
1 безударный слог. Подобные ЭРГ появляются в речи на $30 \%$ чаще, чем ЭРГ с 2-мя безударными и на $67 \%$ чаще, чем ЭРГ с 3-мя безударными. ЭРГ с 4-мя и 5-ю безударными слогами слишком малочисленны, что ставит под сомнение гипотезу об их регулярном появлении в речи. Появление таких РГ от числа ЭРГ составляет 4\% для ЭРГ с 4-мя безударными и 1\% для ЭРГ с 5-ю безударными. Их вероятность среди всех РГ составляет 2\% и 1\% соответственно.

Среди ПЭРГ у мужчин наиболее частыми являются те, которые имеют 1 проклитический и 1 энклитический слоги - 28\% от общего числа ПЭРГ. Далее в порядке убывания частоты появления следуют ПЭРГ с 1-м проклитиком и 2-мя энклитиками (21\%); с 2-мя проклитиками и 2-мя энклитиками (10\%); с 2-мя проклитиками и 1-м энклитиком (9\%); с 1-м проклитиком и 3-мя энклитиками (8\%); с 1-м проклитиком и 4-мя энклитиками (8\%); с 2-мя проклитиками и 3-мя энклитиками (5\%); 3-мя проклитиками и 1-м энклитиком (4\%); с 1-м проклитиком и 5-ю энклитиками, с 2-мя проклитиками и 4-мя энклитиками, с 3-мя проклитиками и 2-мя энклитиками (по 2\%); и 2-мя проклитиками и 5-ю энклитиками (1\%); остальные - 0\% от общего количества ПЭРГ.

Женщины практически полностью повторяют тенденцию, продемонстрированную мужчинами: среди малоиспользуемых ПРГ преобладают те, которые имеют 1 безударный слог. Они употребляются почти в 3 раза чаще, чем ПРГ с 2-мя безударными и около 4,5 раз чаще
ПРГ с 3-мя безударными. ПРГ с 4-мя и 5-ю безударными практически не использовались.

Как и у мужчин, наиболее часто встречаемый вид ЭРГ у женщин - ЭРГ с одним безударным. Далее в порядке убывания следуют ЭРГ с 2-мя, 3-мя, 4-мя и 5-ю безударными слогами.

При сравнении «женских» и «мужских» значений процентных долей и вероятностей ПРГ и ЭРГ с соответствующим количеством безударных слогов достоверных различий не обнаружено. Равно как и не найдено достоверных различий при сравнении количественных составов «женских» и «мужских» ПЭРГ.

\section{Выводы}

«Ритмические репертуары» мужчин и женщин во время неподготовленного чтения вслух почти не различаются. Единственное наблюдаемое достоверное различие - это степень рассеивания количества РГ различных структурных типов в зависимости от типа ударения группообразующего слога, которая, в свою очередь, является следствием различий в формировании акцентной структуры и паузации читаемого текста. Столь однообразные парадигматические свойства слогового ритма, которые продемонстрировали обе группы респондентов, свидетельствуют о малой подверженности данного аспекта просодии гендерному фактору при реализации рассматриваемого вида речевой деятельности.

\section{ЛИТЕРАТУРА}

1. Андросова С.В. Акустические и перцептивные корреляты цельнооформленности слога (экспериментально-фонетическое исследование на материале американской спонтанной речи): Автореф. дисс. ... канд. филол. наук. Санкт-Петербург, 2013. 41 с.

2. Банков А.С. Гендерный фактор в просодическом оформлении речи коммуникантов (экспериментально-фонетическое исследование на материале американского варианта английского языка): дисс. ... канд. филол. наук. Нижний Новгород, 2008. 235 с.

3. Банков А.С. Исследование тембра и его гендерных особенностей с помощью компьютерной программы «Просодия 1.0» // Вестник Нижегородского государственного лингвистического университета им. Н.А. Добролюбова. Вып. 12. - Нижний Новгород: НглУ, 2010. № 4(12). С.11-20.

4. Дечева С.В. Слогоделение в английской речи (когнитивная силлабика): Автореф. дисс. ... канд. филол. наук. Москва, 1995. 45 с.

5. Лингвистический энциклопедический словарь / Гл. ред. В.Н. Ярцева. - М.: Сов. энциклопедия, 1990. 688 с.

6. Пономарева М.А. Слоговое своеобразие фонетики аффектов в американском диатопическом варианте английского языка: Автореф. дисс. ... канд. филол. наук. Москва, 2013. 33 с.

( ) Банков Андрей Сергеевич (bankov2007@yandex.ru). 